\title{
Parasites delay worker reproduction in bumblebees: consequences for eusociality
}

Jacqui A. Shykoff

Paul Schmid-Hempel

Zoologisches Institut der

Universität,

Rheinsprung 9,

CH 4051 Basel, Switzerland
Address reprint requests to J. A. Shykoff, who is now at the Instituut voor Oecologisch Onderzock, Boterhoeksestraat 22, 6666 GA Heteren, The Netherlands.

Received 81 January 1991 Revised 20 April 1991 Accepted 27 April 1991

1045-2249/91/\$4.00

(c) 1991 International Society for Behavioral Ecology

Workers in eusocial insects usually tend the brood of the queen and so achieve representation in the next generation through aiding relatives to reproduce. However, workers of some eusocial species, such as bumblebees, are capable of reproductive activity even in the presence of the queen (in queen-right colonies), and worker reproduction is associated with aggressive behaviors and egg cannibalism, both of which reduce colony efficiency. Thus, factors that affect worker ovarian development, a precondition for reproduction, can influence social harmony and colony productivity. Parasites are a ubiquitous and important part of the biotic environment of all organisms. Here we show that parasites play an important role in the reproductive physiology of worker bumblebees in queen-right colonies of Bombus terrestris, affecting the pattern and timing of ovarian development and oviposition. Workers from colonies parasitized with the intestinal trypanosome Crithidia bombi had less developed ovaries than workers of the same age from unparasitized colonies. In addition, parasitized colonies were smaller than unparasitized colonies for about the first half of colony development. This generated further demographic effects such that workers were on average younger in parasitized than in unparasitized colonies around the time of the onset of worker oviposition, and worker oviposition occurred significantly later in parasitized colonies. Workers in parasitized colonies therefore had lower individual reproductive potential and were cooperative for a larger proportion of the colony cycle than those in unparasitized colonies. In this system, where transmission of the parasite between years probably occurs only in infested, young queens, this effect may represent an adaptation on the part of the parasite to ensure its successful passage through the winter. Parasites, by reducing the cost of worker cooperation, may facilitate queen control over her worker force and play an important role in moderating the social organization of eusocial insect colonies. [Behav Ecol $1991 ; 2: 242-248]$

$\mathrm{R}$ eproductive division of labor within colonies of social insects has puzzled evolutionary biologists since Darwin. Although kin selection theory (Hamilton, 1964) explains the evolution of kin-directed altruism in part, workers should lay eggs when the associated fitness gain outweighs the cost through reduced queen or colony productivity (Hamilton, 1964, 1972). Indeed, worker production of males has been implicated in facilitating the initial establishment of worker behavior (Aoki and Moody, 1981; Iwasa, 1981; Pamilo, 1984). In addition, selection on both queens and workers favors the maintenance of worker reproductive potential to ensure colony reproduction in the event of the death of the queen, especially where orphaning is common (Metcalf, 1980; Owen et al., 1980). However, worker reproduction brings the disadvantage of an evolutionary conflict of interest over male production (Bourke, 1988; Hamilton,
1972; Oster and Wilson, 1978; Ratnieks, 1988), particularly when workers can discriminate between male and female brood (Nonacs and Carlin, 1990). Conflict and reproductive competition are well known within the worker caste (Franks and Scovell, 1983; Ratnieks and Visscher, 1989), particularly in the absence of a queen (Hillesheim et al., 1989; Robinson et al., 1990), as well as between queen and worker (Ishay, 1964; Owen and Plowright, 1982; van Honk et al., 1981). Where reproductive division of labor is not associated with morphological specialization, as in bumblebees, workers can be reproductively active, and conflict is particularly well documented (Owen and Plowright, 1982; van Doorn and Heringa, 1986; van Doorn and Hogeweg, 1985; van Honk et al., 1981).

Bumblebees are annual, eusocial insects, with cooperative brood care, reproductive division of labor, and overlapping generations 
within a colony (Wilson, 1971). Female larvae become queens or workers depending on the quantity of food received (Plowright and Jay, 1977; Röseler, 1970), but events during adult life also affect the reproductive physiology of workers. Ovarian development in worker bumblebees is a function of age (Röseler, 1987) and relates to task (van Doorn, 1987) and dominance rank (van Doorn, 1989; van Doorn and Heringa, 1986). Queens suppress worker ovarian development (van Honk et al., 1980; Röseler et al., 1981), so developed ovaries in bumblebee workers from colonies with an active queen (queen-right) indicate that the queen has lost her dominance, and the hierarchical structure of the colony is dissolving. When workers begin oviposition (i.e., have fully developed ovaries with ripe eggs), they cannibalize eggs and display aggressive behavior toward the queen as well as toward other workers (van Doorn and Heringa, 1986; van Honk et al., 1981), thereby reducing colony efficiency (see also Cole, 1986; Oster and Wilson, 1978). Therefore, factors that affect ovarian development of worker bumblebees could influence the dominance hierarchy, the degree of social harmony, and ergonomic efficiency of the colony.

A number of parasites and parasitoids affect natural populations of bumblebees (Alford, 1975; Schmid-Hempel et al., 1990; Shykoff and Schmid-Hempel, 1991b). Among these is the intestinal trypanosome Crithidia bombi (Lipa and Triggiani, 1980), found in high proportions of workers in summer. Preliminary studies show that prevalence of parasitization in workers increases with time of exposure or worker age in laboratory nests established by infested queens (Shykoff and Schmid-Hempel, 1991a). Transmission occurs when individuals ingest live $C$. bombi cells. These cells are present in the feces of infested bees, so nests become contaminated if individuals defecate in the nest vicinity. As no resting stages of Crithidia species are known (Brun R, personal communication), the $C$. bombi population probably spends the winter only in queens that contracted an infection the previous summer. Thus, the reproductive success of the $C$. bombi in worker bumblebees will depend on queen production of their nest, parasite transmission to those young queens, and the hibernation and subsequent nest founding success of infested queens.

$B$. terrestris queens that failed to lay eggs in the laboratory had less-developed ovaries when infested with $C$. bombi than when uninfested, although nest starting success was independent of infection with this parasite (Shykoff and Schmid-Hempel, 1991b). Thus, some queens are capable of producing successful nests despite the suppressive effects of their parasites. Field investigations, on the other hand, revealed that for foraging summer workers of the species Bombus terrestris $\mathrm{L}$. and $B$. lucorum $\mathrm{L}$., those parasitized with $C$. bombi were more likely to have developed ovaries than were unparasitized workers (Shykoff and Schmid-Hempel, 1991b). Foraging workers represent mixed-age cohorts, as bumblebees show little age polyethism (Brian, 1952). If older workers are both more likely to have developed ovaries and to be infested with this parasite than younger ones, there should be a positive relationship between ovarian development and infestation. Thus, controlled investigations are necessary to determine the relationships among infestation with $C$. bombi, worker age, and ovarian development. We undertook the following study to elucidate these relationships and to investigate a possible role of parasites on social behavior using laboratory nests of $B$. terrestris under queen-right conditions.

\section{METHODS}

In spring 1990 we caught bumblebee queens (B. terrestris) after they had emerged from hibernation and placed them individually in wooden nest boxes in the laboratory (for rearing methods, see Plowright and Jay, 1966). Each day the queens received fresh pollen in the nest and honey-water solution (approximately $50 \%$ ) in the outer feeding box. After they established nests and the first brood workers emerged, we transferred the comb and all bees to perlite observation hives (Pomeroy and Plowright, 1980) and investigated fresh feces from each nest for the presence of Crithidia bombi (Lipa and Triggiani, 1980), which are readily visible under $\times 400$ magnification. In total, 25 nests, 12 uninfested and 13 infested, were reared in the laboratory. Of these, six nests (two without and four with $C$. bombi) were infested with Nosema bombi (Fantham and Porter, 1913) or Mattesia bombi (Liu et al., 1974), so they were excluded from further consideration.

Each day we fed the nests and marked all newly emerged workers with individually numbered Opalith tags to identify them by age. For every nest we recorded the following life-history parameters: date of first male emergence, date of first queen emergence, and presence of worker-laid eggs on the comb. Egg cells produced by workers can be distinguished from those of the queen by their irregular structure. In addition, the presence of more than one open egg cell on the comb indicates that at least two individuals are ovipositing - the queen and one or more workers (Duchateau and Velthuis, 1988).

Between 30 and 35 days after emergence 
Table 1

Bumblebee workers from naturally infested and uninfested nests show different incresse in mean terminal oocyte length with ages

\begin{tabular}{lrrrl} 
Source & df & $\begin{array}{l}\text { Mean } \\
\text { square }\end{array}$ & \multicolumn{1}{c}{$F$} & \multicolumn{1}{l}{$p$} \\
\hline Infestation & 2 & 0.0146 & 0.34 & NS $^{b}$ \\
Age (covariate) & 1 & 8.5301 & 201.89 & .0001 \\
Infestation*age & 1 & 0.4383 & 10.37 & .0015 \\
Error & 199 & 0.0423 & & \\
\hline
\end{tabular}

- Homogeneity of slopes ANCOVA through the origin tested the effects of colony infestation, worker age (covariate), and their interaction on mean terminal oocyte length of bumblebee workers in queen-right colonies.

- Not significant.

of first workers, we sampled approximately 23 workers from each of 5 infested colonies and approximately 18 workers from each of 5 uninfested colonies. These colonies were matched by starting date and size, such that all nests contained about 70 workers on the sampling date (mean $\pm \mathrm{SD}=68.6 \pm 8.9$ ). We sampled workers in a stratified manner, taking at least three individuals of each age. We freeze-killed the workers, dissected them, measured the three largest terminal oocytes with an eyepiece micrometer in a dissecting microscope, and checked fresh wet mounts of intestines at $\times 400$ magnification for the presence of $C$. bombi.

We investigated the relationship between age and prevalence of infection using regression through the origin. To compare the increase in mean terminal-oocyte length with age for workers from infested and uninfested nests, we used a homogeneity of slopes ANCOVA through the origin (Freund et al., 1986;

Table 2

Uninfested and infested nests were respectively homogeneous for increase in mean terminal oocyte length in workers

\begin{tabular}{lrlrl} 
Source & df & $\begin{array}{l}\text { Mean } \\
\text { square }\end{array}$ & $F$ & $p$ \\
\hline Uninfested Nests & & & & \\
$\quad$ Nest & 5 & 0.0095 & 0.96 & NS $^{\star}$ \\
$\quad$ Age (covariate) & 1 & $\mathbf{3 . 8 0 9 3}$ & 142.95 & .0001 \\
$\quad$ Nest*age & 4 & 0.0001 & 0.05 & NS \\
Error & 78 & 0.0266 & & \\
Infested Nests & & & & \\
$\quad$ Nest & 5 & 0.0217 & 0.45 & NS \\
$\quad$ Age (covariate) & 1 & 2.7284 & 56.50 & .0001 \\
$\quad$ Nestage & 4 & 0.0625 & 1.29 & NS \\
Error & 105 & 0.0423 & & \\
\hline
\end{tabular}

- Homogeneity of slopes ANCOVA through the origin tested mean terminal oocyte length of bumblebee workers in uninfested and infested queen-right colonies by nest, worker age (covariate), and their interaction.

- Not significant.
Zar, 1984). In addition, we performed a common quadratic regression on all data because the relation between oocyte length and age was better described by a quadratic than a linear function of age, and we used a $t$ test to compare the residuals from uninfested and infested nests extracted from this common regression analysis. We compared the following life-history parameters between all 9 infested and all 10 uninfested nests using $t$ tests: cumulative worker production over time; total worker, queen, and male production; and the timing of reproductive events.

\section{RESULTS}

Prevalence of infestation increased with worker age in the infested nests [slope (SE) 0.027 $(0.008), F_{(1,23)}=11.254, p=.0028$, from linear regression of arcsin-transformed prevalence data on age]. Oocytes also increased in length with worker age [slope (SE) 0.061 $(0.002), F_{(1,202)}=702.79, p<.0001$, from linear regression). Ovarian development proceeded significantly faster for workers in uninfested than for those in infested colonies (Table 1, Figure 1), and was homogeneous among the five infested and the five uninfested nests, respectively (Table 2). Animals from uninfested nests had significantly larger mean terminal-oocyte lengths than those from infested nests (respectively, $0.89 \pm 0.13 \mathrm{~mm}$, $n=88$ versus $0.59 \pm 0.11 \mathrm{~mm}, n=115$ : mean terminal oocyte length $\pm 95 \% \mathrm{CI}, t=\mathbf{3 . 6 9 8}$, $\mathrm{df}=201, p=.0003$ ). This difference was also evident with the effect of age removed. The residual values from the common quadratic regression of oocyte length on age were larger for animals from uninfested nests than for animals from infested nests (respectively, 0.11 $\pm 0.07, n=88$ versus $-0.17 \pm 0.08, n=$ 115: mean residual $\pm 95 \% \mathrm{CI}$, Welch's $t^{\prime}$ for unequal variance $=5.198$, df $=200, p<$ $.0001)$. Thus, with the effects of age removed, workers from uninfested nests had larger terminal oocytes than those from infested nests.

Most colony life-history traits did not differ for infested and uninfested colonies (Table 3). No significant difference existed between infested and uninfested nests for cumulative worker, queen, or male production. Nor did the total duration of worker production or the timing of emergence of reproductives, either queens or males, differ between the two groups of nests. However, worker-laid eggs appeared in uninfested nests about 5 days earlier than in infested nests (Time measured from emergence of first workers). C. bombi also had significant effects on colony demographic patterns. Worker population size in infested nests was significantly smaller than in uninfested nests for the first 25 days of colony develop- 
ment. Infested nests reached the size of uninfested nests between days 25 and 30 (Figure 2 ). In addition, workers were on average younger in infested nests than in uninfested nests on day $\mathbf{3 5}$ of colony development, at about the time that worker oviposition took place (respectively, $9.59 \pm 0.93, n=9$ versus 11.21 $\pm 1.28, n=10$ : mean age in days $\pm 95 \% \mathrm{CI}$, $t=2.271, \mathrm{df}=17, p=.037$ ) .

\section{DISCUSSION}

Workers in bumblebee nests infested with the trypanosome $C$. bombi were increasingly likely to be infested with increasing age (see also Shykoff and Schmid-Hempel, 1991a). In all colonies, ovarian development in workers was also a function of age (see also Röseler, 1987; van Doorn, 1987). Indeed, although task-related differences in ovarian development do exist, foragers on average showing less ovarian development than do house bees (workers that never leave the nest and perform brood care and other nest activities) (van Doorn, 1987), positive age effects on ovarian development are still observable among foragers. A rank correlation between forager age and oocyte length (data from van Doorn, 1987; Table 1) shows that older foragers have larger oocytes (oocyte length with age: $r_{s}=.89, n=7, p<$ $.005)$. Therefore, the field observation that more infested foragers had developed ovaries than uninfested foragers (Shykoff and SchmidHempel, 1991b) may result from the correlation between both of these traits and worker age.

The relationship between ovarian development and age differed for workers from infested and uninfested nests. The linear analysis showed that mean terminal oocyte length of workers increased faster with age in uninfested than in infested nests (Table 1). Ovary size reached a plateau with increasing worker age, so a quadratic model better described the data (Figure 1). Given the increase in preva-

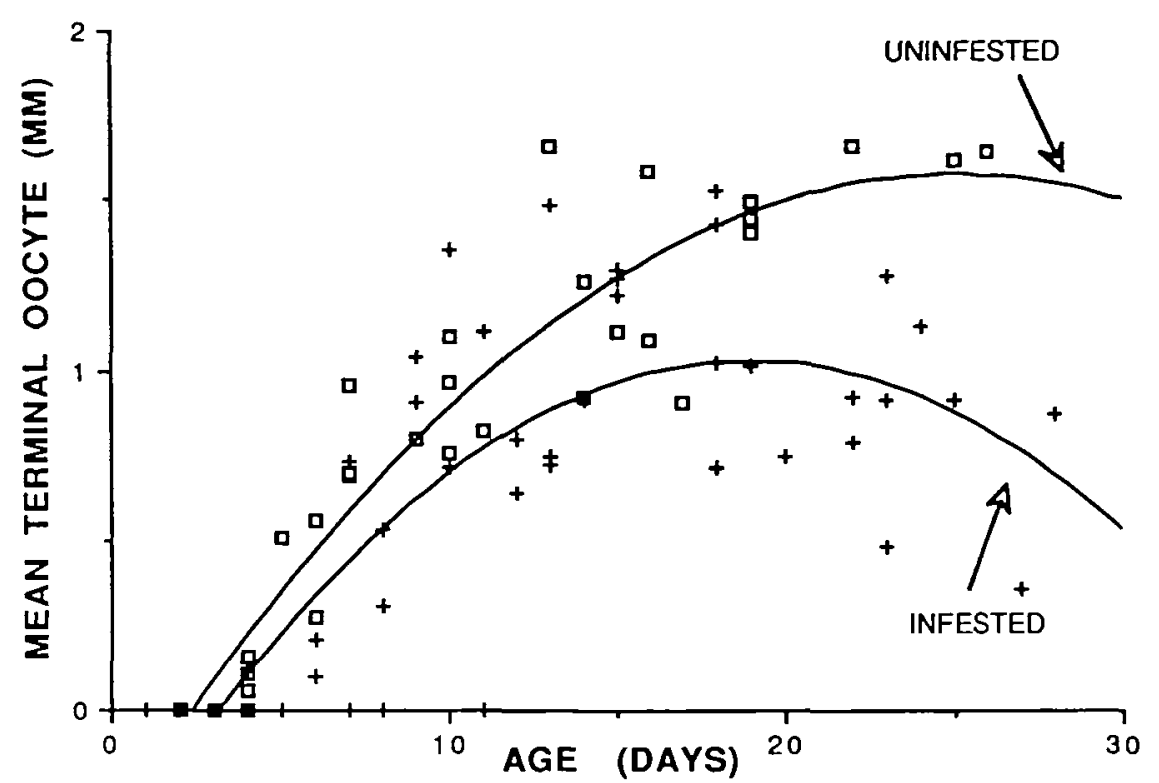

lence of infestation with worker age in laboratory nests, by between 7 and 8 days of age, about half of the workers were infested. If the infestation required a few days to have notable effects on host condition, this would produce the pattern shown here, with ovarian development of workers from infested nests and uninfested nests not measurably different until about 12 days of age.

We do not know if retarded worker ovarian development resulted from a change in the hormonal activity of the queen (van Honk et al., 1980) or of the workers themselves (Röseler et al., 1981). Our data imply direct effects on the workers rather than indirect effects through the queen because the difference in oocyte size between infested and uninfested nests was first obvious in workers from about 12 days old and older. A clear relationship exists among juvenile hormone titer, age, and ovarian development in both queen-right and queenless workers (Röseler, 1977; Röseler and van Honk, 1990), but one must check juvenile
Figure 1

Growth of terminal oocytes in workers from infested and uninfested queen-right bumblebee (Bombus terrestris) colonies. Mean terminal oocyte lengths for workers from each of five infested ( + ) and five uninfested $(\square)$ queenright bumblebee colonies are plotted against worker age. Curves represent the leastsquares best-fit line from a quadratic regression. For uninfested nests: mean oocyte length $=0.097$ (age) -0.001 $\left(\right.$ age $\left.^{2}\right), r^{2}=.79$. For infested nests: mean oocyte length $=$ 0.084 (age) $-0.002\left(\right.$ age $\left.^{2}\right), r^{2}$

Table 3

Life-history parameters of nine naturally infested and ten uninfested bumblebee (Bombus terrestris) colonies

$\begin{array}{lllll}\text { Infested } & \text { Uninfested } & & \\ (\bar{x} \pm 95 \% \mathrm{CI}) & (\bar{x} \pm 95 \% \mathrm{Cl}) & \ell & \text { df } & p\end{array}$

\begin{tabular}{|c|c|c|c|c|c|}
\hline \multicolumn{6}{|l|}{ Cumulative: } \\
\hline $\begin{array}{l}\text { Workers } \\
\text { Queens } \\
\text { Males }\end{array}$ & $\begin{aligned} 116.3 & \pm 38.1 \\
38.0 & \pm 33.5 \\
554.0 & \pm 213.7\end{aligned}$ & $\begin{aligned} 135.7 & \pm 49.2 \\
34.5 & \pm 24.9 \\
431.6 & \pm 144.3\end{aligned}$ & $\begin{array}{l}0.697 \\
0.202 \\
1.107\end{array}$ & $\begin{array}{l}17 \\
11 \\
17\end{array}$ & $\begin{array}{l}\text { NSe } \\
\text { NS } \\
\text { NS }\end{array}$ \\
\hline \multicolumn{6}{|l|}{ Days until: } \\
\hline $\begin{array}{l}\text { First queen emergence } \\
\text { First male emergence } \\
\text { Worker-laid eggs } \\
\text { Last worker emergence }\end{array}$ & $\begin{array}{l}51.7 \pm 5.1 \\
45.7 \pm 6.6 \\
38.2 \pm 2.0 \\
44.7 \pm 4.8\end{array}$ & $\begin{array}{l}48.2 \pm 6.6 \\
44.4 \pm 4.8 \\
33.6 \pm 8.2 \\
46.4 \pm 5.4\end{array}$ & $\begin{array}{l}1.09 \\
0.36 \\
2.72 \\
0.56\end{array}$ & $\begin{array}{l}11 \\
17 \\
17 \\
17\end{array}$ & $\begin{array}{l}\text { NS } \\
\text { NS } \\
.014 \\
\text { NS }\end{array}$ \\
\hline
\end{tabular}

- Not significant. 


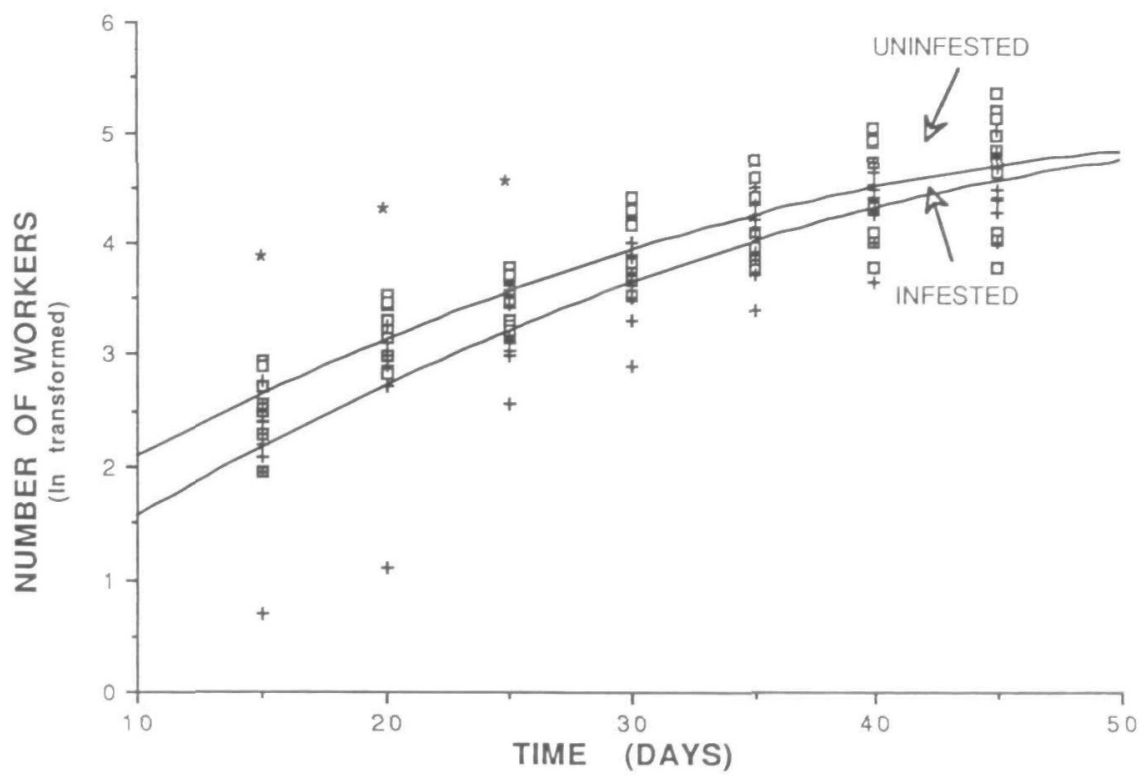

Figure 2

Cumulative growth of bumblebee (Bombrus terrestris) colonies. The cumulative number of workers produced by nine infested $(+)$ and ten uninfested ( $\square$ ) laboratory bumblebee colonies are plotted against number of days after the emergence of the first worker in each colony. On days marked with an asterisk, uninfested colonies had significantly more cumulative workers than infested colonies (two-tailed Wilcoxon test). of this parasite on ovarian development in similar aged workers and facilitating queen dominance. We detected few other differences in life history between infested and uninfested nests (Table 3). Thus, parasite-induced reduction of early colony size had no effect on colony productivity where all nests received surplus food (see also Pomeroy and Plowright, 1982; Müller C and Schmid-Hempel $P$, in preparation). In the field, however, depressed early colony growth could be detrimental because small colonies are more sensitive to inclement weather and social parasites (Fisher, 1984; Müller C, personal communication). Also, because colony growth relies on resources collected by the worker force, low worker numbers mean lower resource input, and hence reduced further growth (Heinrich, 1979).

Because only large field colonies produce queens (Owen et al., 1980), natural colonies with reduced early worker production may be able to reproduce solely via males, the less costly sex. This modification of colony performance would be detrimental for both parasite and host. Reproduction through males alone would represent a dead end for the parasites in an infested colony if parasite transmission between years relies on the survival and success of young queens from infested nests. Thus, selection on the parasite would favor traits that enable infested bumblebee colonies to produce queens despite unavoidable negative effects of parasites, and selection on the hosts should favor reproduction via both males and queens. In this example, where both parasite and host benefit from colony queen production, the extended phenotype of the parasitized host (Dawkins, 1982) should evolve to that which minimizes or compensates the negative effects of parasites on colony queen production.

Crithidia bombi influenced colony demography, worker ovarian development, and the timing of worker oviposition. In this way the parasite subtly increased the degree of differentiation between queen and worker and reduced worker reproductive potential. By decreasing the reproductive ability of an individual worker, this parasite concomitantly lowered the cost of worker altruism because this cost is measured in lost reproductive opportunity. Thus, modification of worker reproductive physiology can render the workers in parasitized colonies more social and cooperative. In a social insect species where workers are capable of laying fertile eggs, such parasites will promote intracolony cooperation and facilitate queen control over her workers, so long as the negative effect on queen dominance ability is relatively small. Therefore, parasites could play an important role 
in structuring the social organization of eusocial insect colonies, particularly in species where morphology does not preclude worker production.

We thank A. Blarer and H. Gramm for help in the laboratory. A. Baur, S. Durrer, E. Hillesheim, C. Müller, A. van Noordwijk, R. Schmid-Hempel, and two anonymous reviewers provided constructive criticism on previous drafts of this paper. Financial support was provided by Swiss National Science Foundation grants 3.017-0.87 and $31-25692.88$ to P. S.-H.

\section{REFERENCES}

Alford DV, 1975. Bumblebees. London: Davis Poynter. Aoki K, Moody M, 1981. One- and two-locus models of the origin of worker behavior in Hymenoptera. J. Theor Biol 89:449-474.

Bourke AFG, 1988. Worker reproduction in the higher eusocial Hymenoptera. Q Rev Biol 63:291-311.

Brian AD, 1952. Division of labour and foraging in Bombus agrorum Fabricius. J Anim Ecol 21:223-240.

Cole BJ, 1986. The social behavior of Leptothorax allardyces (Hymenoptera, Formicidae): time budgets and the evolution of worker reproduction. Behav Ecol Sociobiol 12:165-173.

Dawkins R, 1982. The extended phenotype. Oxford: Oxford University Press.

Duchateau MJ, Velthuis HHW, 1988. Development and reproductive strategies in Bombus terrestris colonies. Behaviour 107:186-207.

Fantham HB, Porter A, 1913. The morphology, biology and economic importance of Nasema bombi, parasitic in various humble bees (Bombus spp.) Ann Trop Med Parasitol 8:623-638.

Fisher RM, 1984. Evolution and host specificity: a study of the invasion success of a specialized bumblebee social parasite. Can J Zool 62:1641-1644.

Franks NR, Scovell E, 1983. Dominance and reproductive success among slave-making worker ants. Nature 304: 724-725.

Freund RJ, Littel RC, Spector PC, 1986. SAS system for linear models, 1986 ed. (Crum L, ed). Cary, North Carolina: SAS Institute Inc.

Hamilton WD, 1964. The genetical evolution of social behaviour. I and II. J Theor Biol 7:1-16;17-52.

Hamilton WD, 1972. Altruism and related phenomena mainly in social insects. Ann Rev Ecol Syst 3:193-232.

Heinrich B, 1979. Bumblebee economics. Cambridge: Harvard University Press.

Hillesheim E, Koeniger N, Moritz RFA, 1989. Colony performance in honeybees (Apis mellifera capensis Esch.) depends on the proportion of subordinate and dominant workers. Behav Ecol Sociobiol 24:291-296.

Ishay JS, 1964. Observations sur la biologie de la guêpe orientale Vespa orientalis. Insectes Soc 11:193-206.

Iwasa $Y, 1981$. The role of sex ratio in the evolution of eusociality in haplodiploid social insects. J Theor Biol 93:125-142.

Lipa JJ, Triggiani O, 1980. Crithidia bombi sp. n. a flagellated parasite of a bumble-bee Bombus terrestris L. (Hymenoptera, Apidae). Acta Protozool 27:287-290.

Liu HJ, Macfarlane RP, Pengelly DH, 1974. Mattesia bombi n. sp. (Neogregarinida: Ophrocystidae), a parasite of Bombus (Hymenoptera: Apidae). J Invert Pathol 32:225281.

Metcalf RA, 1980. Sex ratios, parent-offspring conflict, and local competition for mates in the social wasps Polistes metricus and Polistes variatus. Am Nat 116:642654.

Nonacs P, Carlin NF, 1990. When can ants discriminate the sex of brood? A new aspect of queen-worker conflict. Proc Natl Acad Sci USA 87:9670-9673.

Oster G, Wilson EO, 1978. Caste and ecology of social insects. Princeton: Princeton University Press.

Owen RE, 1988. Body size variation and optimal body size of bumble bee queens (Hymenoptera: Apidae). Can Entomol 120:19-27.

Owen RE, Plowright RC, 1982. Worker-queen conflict and male parentage in bumble bees. Behav Ecol Sociobiol 11:91-99.

Owen RE, Rodd FH, Plowright RC, 1980. Sex ratios in bumble bee colonies: complications due to orphaning? Behav Ecol Sociobiol 7:287-291.

Pamilo P, 1984. Genetic relatedness and the evolution of insect sociality. Behav Ecol Sociobiol 15:241-248.

Plowright RC, Jay SC, 1966 . Rearing bumble bee colonies in captivity. J Apic Res 5:155-165.

Plowright RC, Jay SC, 1977. On the size determination of bumble bee castes (Hymenoptera: Apidae). Can J Zool 55:1133-1138.

Pomeroy N, Plowright RC, 1980. Maintenance of bumble bee colonies in observation hives (Hymenoptera: Apidae). Can Entomol 112:321-326.

Pomeroy N, Plowright RC, 1982. The relation between worker numbers and the production of males and queens in the bumble bee Bombus perplexus. Can J Zool 60: 954-957.

Ratnieks FLW, 1988. Reproductive harmony via mutual policing by workers in eusocial Hymenoptera. Am Nat 132:217-236.

Ratnieks FLW, Visscher PK, 1989. Worker policing in the honeybee. Nature 342:796-797.

Robinson GE, Page RE, Fondrk MK, 1990. Intracolonial behavioral variation in worker oviposition, ophagy, and larval care in queenless honey bee colonies. Behav Ecol Sociobiol 26: 315-323.

Röseler P-F, 1970. Unterschiede in der Kastendetermination zwischen den Hummelarten Bombus hypromum und Bombus terrestrus. Z Naturforsch 78:175-198.

Röseler P-F, 1977. Juvenile hormone control of oogenesis in bumblebee workers, Bombus terrestris. J Insect Physiol 23:985-992.

Röseler P-F, 1987. Größenpolymorphismus, Geschlechtsregulation und Stabilisierung der Kasten im Hummelvolk. In: Sozialpolymorphismus bei Insekten, 2nd ed (Schmidt GH, ed). Stuttgart: Wissenschaftiche Verlag mbH; 298-335.

Röseler P-F, Rōseler I, van Honk CGJ, 1981. Evidence for inhibition of corpora allata activity in workers of Bombrus terrestris by a pheromone from the queen's mandibular glands. Experientia 37:348-351.

Röseler P-F, van Honk CGJ, 1990. Castes and reproduction in bumblebees. In: Social insects: an evolutionary approach to castes and reprodution. (Engles $W, e d$ ). Berlin: Springer-Verlag; 147-166.

Schmid-Hempel P, Müller C, Schrnid-Hempel R, Shykoff $J A, 1990$. Incidence and ecological correlates of parasitism by conopid flies (Conopidae, Diptera) in populations of bumblebees. Insectes Soc 37:14-30.

Shykoff JA, Schmid-Hempel P, 1991a. Genetic relatedness and eusociality: parasite-mediated selection on the genetic composition of groups. Behav Ecol Sociobiol 28:371-376.

Shykoff JA, Schmid-Hempel P, 1991b. Incidence and effects of four parasites in natural populations of bumble bees in Switzerland. Apidologie 22:117-125.

Sutcliffe GH, Plowright RC, 1988. The effects of food supply on adult size in the bumble bee Bombus terricola K. (Hymenoptera: Apidae). Can Entomol 120:10511058.

van Doom A, 1987. Investigations into the regulation of dominance behaviour and of the division of labour in bumble bee colonies (Bombus terrestris). Neth J Zool 97: 255-276.

van Doom A, 1989. Factors influencing dominance be- 
haviour in queenless bumblebee workers (Bombrus terrestris). Physiol Entomol 14:211-221.

van Doorn A, Heringa J, 1986. The ontogeny of a dominance hierarchy in colonies of the bumblebee Bombrus terrestris (Hymenoptera, Apidae). Insectes Soc 33:3-25. van Doorn A, Hogeweg P, 1985. Die Entwicklung des agonistischen Verhaltens innerhalb der Arbeiterinnenkaste und zwischen Arbeiterinnen und der Königin während der Volksentwicklung bei der Erdhummel, Bombus terrestris. Mitt Dtsch Ges Allg Angew Entomol 4:328-331.

van Honk CGJ, Röseler P-F, Velthuis HHW, Hoogeveen $\mathrm{JC}, 1981$. Factors influencing the egg-laying of workers in a captive Bombrus terrestris colony. Behav Ecol Sociobiol 9:9-14.

van Honk CGJ, Velthuis HHW, Röseler P-F, Malotaux $M E, 1980$. The mandibular glands of Bombus Lerrestris queens as a source of queen pheromones. Entomol Exp Appl 28:191-198.

Wilson EO, 1971. The insect societies. Cambridge: Harvard University Press.

Zar JH, 1984. Biostatistical analysis, 2nd ed. Engelwood Cliffs, New Jersey: Prentice Hall. 